\title{
The Role of the CJEU in Harmonizing EU Copyright Law
}

\author{
Raquel Xalabarder
}

Published online: 5 September 2016

(C) Max Planck Institute for Innovation and Competition, Munich 2016

In recent years, the Court of Justice of the European Union (CJEU) has issued some interesting and controversial rulings interpreting and further harmonizing EU copyright law. In addition to shaking up a few traditional concepts that were regarded as unquestionable, the Court has often applied new criteria, sometimes foreign, to traditional copyright law. Such criteria include the proportionality principle, securing the purpose and goal of the provision and a "de minimis" requirement, and these have allowed the Court to introduce some much-needed flexibility at a time when copyright laws are not always prepared to meet the challenges posed by technologically changing contexts. In addition, the Court has often chosen to qualify as "autonomous concepts of EU law" provisions that were not clearly apparently so in the Directives.

By doing so, the CJEU has found an express route to further strengthen and harmonize the fragmented and sometimes inconsistent EU copyright acquis, resulting from the subsidiarity principle that has so far led harmonization in this area. The concept of communication to the public and the scope of the exceptions and limitations to exclusive rights provide some good examples of this pattern.

It was not until the InfoSoc Directive 2001/29/EC that the concept of communication to the public was substantially, but partially, ${ }^{1}$ harmonized in the EU - without prejudice to the existing Directives - to cover any transmission of a work to the public in a non-tangible form, including the "making available to the public."

Since then, the Court has had several opportunities to interpret and harmonize this concept, both in analogue and digital contexts. The concept of "public" is

\footnotetext{
${ }^{1}$ Notice that the harmonized scope does not cover the acts of communication that take place "in situ" (performance, display, etc.).
}

R. Xalabarder $(\bowtie)$

Professor

Chair of Intellectual Property, Universitat Oberta de Catalunya, Barcelona, Spain

e-mail: rxalabarder@uoc.edu 
paramount to interpret the scope of this exclusive right and the Court has consistently interpreted it restrictively, as requiring an "undetermined number of potential listeners" (meaning "persons in general, not restricted to individuals belonging to a private group") and implying "a fairly large number of persons," (excluding "groups of persons which are too small or insignificant" but allowing for the public to be "successive" over time).

In addition the Court has turned to other "complementary criteria" to assess the scope of this right, such as the profit-making nature of the activity (it does not determine the existence of the act but "it is not irrelevant" and must be taken into account), the existence of an intentional, deliberate and "indispensible" intervention by the operator (without this intervention, the customers would not be able to enjoy the work), the existence of a "new public", which was not taken into account by the copyright holders when they authorised the initial communication, and the existence of "new technical means different from that of the original communication".

Through these criteria the CJEU has introduced some "de minimis" requirements in the interpretation of the exclusive rights. One might argue that the very concept of "exploitation" should already inherently cast some restriction as to which acts fall within the scope of exclusivity granted to the author; however, this is not always apparent in copyright laws, and the interpretation given by the CJEU in this area is, thus, rather innovative.

After an overall assessment of all these criteria, the Court has concluded that the transmission of TV or radio broadcast signals to a bar or place open to the public $(F A P L)$, or to the private rooms of a hotel $(S G A E)$ or to the public rooms in a rehabilitation center (Reha Training) qualify as acts of communication to the public in all EU States, and so does the online live-streaming of TV broadcasts (TV Catchup); while, instead, transmission of a radio broadcast to the waiting room of a private dentist does not qualify as such (Del Corso). Despite the apparent inconsistency, the different outcomes can be easily explained because of the factual differences among the cases, not because of different criteria used by the Court.

The same criteria are being used to assess if linking qualifies as an act of communication to the public.

A link is nothing but a shortcut to access contents online. It may take several shapes and forms: links may be deep, framed, they may be individually provided, aggregated or listed as results from a search done by the user (online search engines cannot be understood without linking), and may be made to lawfully posted contents as well as to unlawfully posted (infringing) contents. Anything that happens online involves, in some manner or another, a link.

The qualification of linking as an act of "communication to the public" is especially delicate because, on the one hand, copyright infringement occurs increasingly online and linking to this infringing content clearly increases the damage caused, and on the other hand, this activity will have a direct impact on the development of new platforms and markets of exploitation as well as on the individual exercise of other fundamental rights such as freedom of speech, information and access to culture. 
Some may choose to favor more "nuanced" (and complex) answers that take into account all these parameters, ${ }^{2}$ possibly having in mind the interests of the copyright owners and the pressing need to put an end to online "piracy" and websites linking to infringing contents. Others, instead, may prefer clear and simple rules and avoid qualifying linking as an exclusive right, ${ }^{3}$ perhaps also having in mind the myriad of non-infringing uses that linking entails.

The CJEU has been balancing the several interests at stake when dealing with links online by applying the criteria stated above. The one criterion especially important here has been that of a "new public". This requirement, taken from the Guide to the Berne Convention to justify "the public communication by a loudspeaker ... of a broadcast of the work" as an exclusive act, was first used by Judge Malenovsky in the 2006 case SGAE v. Rafael Hoteles, and used later - also by judge Malenovsky - in 2012 (PPL) and in 2014 (Svensson). The application of this criterion in $S G A E$ and $P P L$ came naturally since both cases dealt with the distribution of TV broadcast signals to hotel bedrooms. In both cases the Court concluded in favor of the existence of an act of communication to the public. The Svensson case, however, dealt with the provision of links to contents available online, and the Court used the "new public" criterion, together with the "indispensible intervention", to conclude precisely the opposite: no communication to the public exists as long as the linking (or framing) ${ }^{4}$ is done to content that is "freely available" online.

In another case still pending (GS Media), the Court will have the opportunity to reconsider these criteria and expressly decide if the same conclusion applies regardless of the lawful or unlawful nature of the "freely available" contents posted at origin. ${ }^{5}$ So far, Advocate General Wathelet has confirmed so, by stressing the importance of the "indispensible intervention" criterion ("it is not sufficient that the hyperlink facilitates or simplifies users' access to the work") over the "new public" criterion (since it can only be applied when the original posting has been authorized by the right holder). The AG explains that linking is "both systematic and necessary for the current internet architecture", and imposing a requirement on the person who provides the link to ascertain if the initial posting was duly authorized would be "to the detriment of the proper functioning of the internet". The AG further reminds us that copyright enforcement measures are available against the direct infringer and can be supported by means of injunctions addressed to the intermediaries - which are best placed to bring such infringing activities to an end. Furthermore, the websites providing these links will unlikely be exempted under the strict conditions of "mere intermediary" and "merely technical, automatic and passive nature" set for these new web 2.0 ISPs to benefit from the hosting safe harbor (L'Oréal).

\footnotetext{
${ }^{2}$ As the ALAI supports in its successive opinions. See http://www.alai.org/en/resolutions-and-positions. html.

3 As the ECS supports in its opinion on the Svensson case. See https://europeancopyrightsociety.org/howthe-ecs-works/ecs-opinions/.

4 The same conclusion applies to "framing," to the extent that there is no "new public" and that there is no "new technical means" different from the original communication (the initial posting of the work online). See Svensson (recital 29) and the CJEU Order in BestWater.

5 Notice that the court has already implicitly confirmed so in both Svensson and BestWater.
} 
The opinion of the AG appears to be an elegant, balanced and simple solution that takes into account the crucial role of linking for the functioning of Internet and the different interests at stake. It avoids turning every user into either an infringer or a licensee, and at the same time ensures that effective measures for the enforcement of copyright may be used against those who knowingly, willingly, and mostly for profit, infringe copyright. ${ }^{6}$ Copyright law will only work in the Internet to the extent that it is accepted and respected by society as a good law. If we want it to survive in online contexts, copyright rules need to be clear, simple, balanced and in accordance with social norms. By confirming the AG's opinion, the CJEU would be doing so.

Other examples of the innovative work done by the CJEU in harmonizing EU copyright can be found in the realm of limitations and exceptions, under Art. 5 InfoSoc Directive. Despite the lack of formal harmonization in this area, the CJEU has found here fertile ground for its innovative rulings.

Leaving aside the technical copies in Art. 5(1), the limitations listed in Art. 5 are not mandatory for Member States, but they are obliged to comply with the three-step test when applying them. This test, as designed and reshaped over time from Art. 9(2) BC to Art. 5(5) InfoSoc Directive, has been used as a beacon for the scholarly prescription that, unlike exclusive rights, "limitations and exceptions" must solely and always be interpreted restrictively. The CJEU has expressly rejected such a restrictive reading and has even turned to other criteria to interpret the scope and application of limitations, such as the principle of proportionality in the enforcement of copyright in a manner that is balanced with other fundamental rights and public interests at stake, and the need to safeguard the "effectiveness and the purpose" of the limitation. ${ }^{7}$ These criteria correspond to general hermeneutical principles which, nevertheless, had not traditionally been favored within copyright law to interpret the scope and application of limitations.

But perhaps the most striking feature brought by the CJEU in this area is the "express" harmonization achieved by qualifying the list of limitations in Art. 5 as "autonomous concepts of EU law" and, as such, by imposing its uniform interpretation throughout the EU, regardless of what national laws convey. In other words, Member States may choose which limitations to implement in their national laws, but they cannot freely design their scope: the scope of limitations comes "standardized" as designed in the corresponding paragraph of Art. 5. The CJEU has concluded so in two paramount cases dealing with the limitations of quotation (Painer) and parody (Deckmyn). In both cases, national laws had stricter requirements than those envisioned in Art. 5(3)(d) and (k), respectively; the Court expressly set aside the national laws and applied the harmonized scope of the limitations as designed in Art. 5.

This conclusion may be criticized as contrary to the formal harmonization achieved by the InfoSoc Directive, but it cannot be denied that the final legislative compromise fell short of the initial ambitious harmonizing goal for limitations, and that satisfying the needs of the internal market requires further harmonization not

\footnotetext{
6 The CJEU will specifically consider this issue in two other pending cases dealing with the Pirate Bay website: Stiching Brein I and II.

7 See Promusicae, Painer, FAPL, Deckmyn and Darmstadt.
} 
only of the rights but also of the exceptions and limitations. ${ }^{8}$ The CJEU conclusion is in harmony, if not with the enacting language in the InfoSoc Directive, with its harmonizing goal and achieves what the EU legislator failed to achieve.

Some call the CJEU an "activist" court, others assert that it is going "too far" and stepping on the role of the EU legislator (which, silently, seems to be quite content with this). However, taking into account the partial, fragmented and slow harmonization achieved through the subsidiarity principle, and considering that full harmonization of copyright in the EU in the form of a single copyright code and title - as available under Art. 118 TFEU - appears to be a "long-term target", 9 one can only welcome the efforts of the CJEU and acknowledge its fundamental role in harmonizing EU copyright.

\footnotetext{
${ }^{8}$ See recital 31, "existing differences in the exceptions and limitations ... have direct negative effects on the functioning of the internal market".

9 See the Commission in its Communication "Towards a modern, more European copyright framework" $\operatorname{COM}(2015) 626$ final.
} 